\title{
Erratum to: Detecting fludioxonil residues in brown rice and rice straw using gas chromatography-nitrogen phosphorus detector
}

\author{
Ah-Young Ko • A. M. Abd El-Aty • \\ Jin Jang · Jeong-Heui Choi • Md. Musfiqur Rahman • \\ Sung-Woo Kim • Ho-Chul Shin · Jae-Han Shim
}

Published online: 10 April 2015

(C) The Korean Society for Applied Biological Chemistry 2015

Erratum to: J Korean Soc Appl Biol Chem (2015)

58(2):213-217

DOI 10.1007/s13765-015-0040-z

The affiliation of one of the corresponding author, A.M. Abd El-Aty, has been changed. The current affiliation is given in this erratum.

The online version of the original article can be found under doi:10.1007/s13765-015-0040-z.

A.-Y. Ko · J. Jang · J.-H. Choi · Md. M. Rahman .

S.-W. Kim · J.-H. Shim $(\bowtie)$

Biotechnology Research Institute, Chonnam National

University, 77 Yongbong-ro, Buk-gu, Gwangju 500-757,

Republic of Korea

e-mail: jhshim@jnu.ac.kr; jhshim@chonnam.ac.kr

\section{A.-Y. Ko $\cdot$ J. Jang}

Pesticide \& Veterinary Drug Residue Division, National Institution of Food and Drug Safety Evaluation, 187, Ohsongeup,

Cheongwon-gun, Chungcheongbuk-do 363-700,

Republic of Korea
A. M. Abd El-Aty $(\bowtie) \cdot$ H.-C. Shin
Department of Veterinary Pharmacology and Toxicology,
College of Veterinary Medicine, Konkuk University, 1
Hwayang-dong, Kwangjin-gu, Seoul 143-701,
Republic of Korea
e-mail: abdelaty44@hotmail.com 